\title{
Nominalisasi Pada Iklan Lowongan Pekerjaan Berbahasa Inggris Di Surat Kabar Indonesia
}

\author{
Krisna Yudha Bakhti, Siti Yuliah \\ Jurusan Bahasa Inggris, Politeknik Negeri Bandung, Indonesia \\ Email: krisna.yudha@polban.ac.id, siti.yuliah@polban.ac.id
}

\begin{abstract}
RINGKASAN
Penelitian ini menganalisis 50 buah iklan lowongan pekerjaan berbahasa Inggris di surat kabar Indonesia. Penelitian ini bertujuan untuk mengidentifikasi struktur nominalisasi dan penggunaannya pada iklan lowongan pekerjaan. Documentary study digunakan untuk menganalisis data penelitian. Hasil analisis menunjukkan bahwa struktur nominalisasi yang terdapat pada iklan lowongan pekerjaan adalah struktur yang kompleks karena struktur tersebut terdiri atas head yang dipremodifikasi oleh deitic, numerative, epithet, dan classifier dan diposmodifikasi oleh frase preposisi. Selain itu, hasil penelitian juga menunjukkan bahwa penggunaan nominalisasi ditemukan di semua bagian iklan.
\end{abstract}

Kata kunci: nominalisasi, iklan lowongan pekerjaan

\begin{abstract}
This study analyzed job advertisements written in English. The study is intended to identify the structure of nominalisation and its use in the job advertisements. In order to reach this objective, the researchers selected 50 job advertisements that published on two newspapers in Indonesia; Pikiran Rakyat and Kompas. The selected data were analysed for their nominalisation structure. The qualitative research of documentary study was applied. The result indicates that the nominalisation found in the job advertisements are the complex ones. They are constructed from a head, pre-modified by deictic, numerative, epithet and classifier, and post-modified by a prepositional phrase. In addition, the result also showed that the nominalisations were used in every part of job advertisements.
\end{abstract}

Key words: nominalisation, job advertisement.

\section{PENDAHULUAN}

Iklan lowongan pekerjaan sangat memberikan manfaat baik bagi perusahaan maupun masyarakat. Bagi perusahaan, iklan lowongan pekerjaan merupakan media yang tepat untuk menyebarluaskan informasi terkait kesempatan bekerja yang ditawarkan oleh perusahaan sehingga perusahaan bisa mendapatkan calon pegawai yang berkualitas dan 
sesuai dengan standar. Sementara itu, bagi masyarakat iklan lowongan pekerjaan sangat membantu mereka untuk mendapatkan informasi tentang kesempatan bekerja dan jenis pekerjaan yang sesuai dengan keahliannya.

Berbeda dengan iklan komersial yang menampilkan pesan teks dan gambar, iklan lowongan pekerjaan hanya menampilkan pesan teks. Pesan teks tersebut merupakan elemen yang paling penting sehingga informasi yang disampaikan khususnya pada bagian persyaratan, kualifikasi, dan keuntungan dari pekerjaan yang ditawarkan harus ditulis semenarik mungkin (RSI: 2013).

Menulis informasi atau pesan dalam iklan lowongan pekerjaan agar dapat menarik perhatian para pencari kerja merupakan hal yang tidak mudah karena iklan lowongan pekerjaan harus dibuat dengam mempertimbangkan pemilihan kata yang digunakan. Teks yang digunakan dalam iklan harus singkat, tetapi tetap menggambarkan tujuan, tindakan, dan sensibilitas yang dapat memengaruhi pembaca untuk merespon iklan tersebut (Vaicenoniene: 2006). Hal ini disebabkan sebagian besar pembaca iklan lowongan pekerjaan tidak tertarik untuk membaca teks yang terlalu panjang. Mereka hanya membaca dengan cepat untuk mengetahui kualifikasi dan persyaratan yang dibutuhkan untuk melamar pekerjaan yang ditawarkan (RSI: 2013).

Sejalan dengan Vaicenonience, Romanenko (2014) juga menyatakan bahwa kalimat yang sederhana dan pendek adalah salah satu ciri bahasa iklan. Bahasa tersebut mampu memberikan efek empati dan memudahkan para pembaca untuk memahami pesan yang disampaikan. Bahasa yang sederhana ini biasanya terdiri atas satu klausa dengan satu subjek dan verba maupun berupa nominal.

Penelitian terkait iklan lowongan pekerjaan di media cetak telah dilakukan oleh beberapa peneliti terdahulu. Lapsanska (2006) menganalisis frasa nomina pada iklan di media cetak. Dalam penelitian tersebut, ditemukan bahwa struktur nominalisasi jauh lebih kompleks dibandingkan dengan struktur lainnya. Selain itu disebutkan juga bahwa hal yang menarik dari penggunaan nominalisasi terletak pada bagian premodifier yang biasanya sangat kompleks. Hal ini bertujuan untuk menggambarkan dan menjelaskan secara spesifik informasi yang dimuat dalam iklan. Sejalan dengan Lapsanska, Leech (1966) mengemukakan bahwa bagian yang menarik dari nominalisasi adalah bagian premodifier. Hal ini disebabkan premodifier memiliki kompleksitas dan struktur yang 
tidak biasa. Premodifier terdiri atas nomina yang jumlahnya tidak terbatas. Alasan penggunaan premodifier dalam sebuah iklan adalah karena premodifier tidak hanya memberikan informasi yang diiklankan, tetapi juga memberikan gambaran yang menarik tentang hal yang diiklankan.

Berdasarkan penjelasan tersebut, penulis meneliti penggunaan bahasa pada iklan lowongan pekerjaan berbahasa Inggris di Indonesia khususnya penggunaan nominalisasi, dengan tujuan untuk:

1. mengidentifikasi truktur nominalisasi yang terdapat pada iklan lowongan pekerjaan berbahasa Inggris di surat kabar di Indonesia,

2. Mendeskripsikan penggunaan nominalisasi pada iklan lowongan pekerjaan tersebut.

Hasil penelitian ini diharapkan dapat meningkatkan pemahaman dan keterampilan dalam membuat iklan lowongan pekerjaan berbahasa Inggris.

\section{TINJAUAN PUSTAKA}

\section{Struktur Iklan Lowongan Pekerjaan}

Iklan lowongan pekerjaan merupakan salah satu jenis iklan yang dapat ditemukan di surat kabar, majalah, dan bahkan internet dengan tujuan untuk menawarkan suatu pekerjaan. Untuk menarik perhatian para pencari kerja, iklan lowongan pekerjaan perlu dibuat semenarik mungkin dan harus meliputi berbagai informasi yang sesuai dengan kebutuhan. Menurut Dessler (2013), ukuran iklan harus optimal, tidak melebihi 500 kata karena iklan yang terlalu panjang akan membosankan pembaca. Iklan lowongan pekerjaan juga harus memiliki judul yang menarik yang menggambarkan jenis pekerjaan yang ditawarkan.

Iklan lowongan pekerjaan terdiri atas empat kerangka dasar, yaitu identitas perusahaan, nama posisi/pekerjaan yang ditawarkan, informasi tentang kualifikasi/persyaratan yang harus dimiliki calon pelamar, dan informasi tentang tata cara melamar pekerjaan (Rafaeli dan Oliver dalam Kheovichai: 2013). Keempat kerangka dasar tersebut ditulis dalam bentuk teks dengan struktur teks berupa frasa dan kalimat sederhana (RSI: 2013). Frasa adalah kelompok kata yang memiliki makna dan dapat membentuk klausa atau kalimat (Knapp and Watkins: 2009). Sementara itu, kalimat 
adalah kelompok kata yang digunakan untuk menyampaikan gagasan dan terdiri atas satu klausa atau lebih serta memiliki makna lengkap (Oshima dan Hogue: 2006).

\section{Nominalisasi}

Nominalisasi adalah cara untuk mengekspresikan konseptualisasi dari suatu proses atau keadaan dalam bentuk nominal secara linguistik (Bello: 2016). Menurut Martin (1991), nominalisasi adalah ungkapan sebagai frase nomina yang lebih sering diekspresikan dalam kata kerja, kata sifat, atau klausa keseluruhan. Eggins (2004: 94) menyatakan bahwa nominalisasi adalah proses mengubah hal-hal yang biasanya bukan nomina menjadi nomina. Dengan demikian, nominalisasi adalah kata benda yang berasal dari kategori leksikal lain (part of speech).

Didasarkan pada register ilmiah dan jurnalistik, penggunaan nominalisasi dapat memberikan beberapa konsekuensi yang positif untuk teks itu sendiri. Konsekuensi tersebut antara lain penggunaan nominalisasi dapat meningkatkan kohesi leksikal dan koherensi ide yang akhirnya memberikan manfaat untuk struktur teks (Bello: 2016), menyampaikan informasi dengan lebih objektif dan impersonal, dan membuat teks lebih ringkas dengan mengemas banyak informasi menjadi beberapa kata sehingga teks akan lebih abstrak dan formal (Cooper: 2010).

Nominalisasi dalam artikel ini adalah nominalisasi untuk things atau head noun dalam kelompok nominal. Kelompok nominal meluas secara leksikal dengan modifikasi yang mencakup struktur fungsional: "Deictic - Numerative - Epithet - Classifier - Thing - Qualifier" (Halliday:1985).

Dalam Knapp dan Watkins (2009), nominalisasi dapat dibentuk oleh tiga struktur fungsional dasar, yaitu premodifier, head, dan postmodifier. Premodifier adalah kata atau kelompok kata yang terletak sebelum head noun atau thing (deitic, numerative, epithet, dan classifier), postmodifier adalah kata atau kelompok kata yang terletak setelah head noun atau thing (qualifier). Berikut adalah contoh nominalisasi yang terdiri atas premodifier, head, dan postmodifier.

\begin{tabular}{|c|c|l|}
\hline An excellent & understanding & $\begin{array}{l}\text { of Human Resources or employee } \\
\text { legislation }\end{array}$ \\
\hline premodifier & head & \multicolumn{2}{|c|}{ postmodifier } \\
\hline
\end{tabular}




\begin{tabular}{|l|c|c|}
\hline high & degree & $\begin{array}{l}\text { of personal and professional integrity in the } \\
\text { workplace }\end{array}$ \\
\hline premodifier & head & postmodifier \\
\hline
\end{tabular}

Premodifier terdiri atas empat elemen dasar, yaitu deictic, numerative, epithet, dan classifier. Deictic adalah kata atau frasa yang mengacu ke waktu, tempat, dan situasi. Fungsi deictic ditentukan oleh determiner. Deictic dibagi menjadi dua kelompok, yaitu specific deictic ( $a$, an, one, no, dan each) dan non-specific deictic (the, those, his, her, whose).

Contoh:

1. an excellent understanding of HR/employee legislation

2. the ability to understand company business performance

3. a related technical discipline

Numerative adalah kata atau frasa yang mengacu ke angka atau jumlah, misalnya many, several, few, lots of.

Contoh:

4. ten years experience in Human Resource Management

5. seven years experience with research and development

Epithet mengacu pada karakteristik atau kualitas yang dimiliki oleh suatu benda (head), misalnya excellent, strong, good, dan fast.

Contoh:

\section{Excellent communication skill}

7. An advanced english level in writing and speaking

Classifier adalah kata dalam nominalisasi yang menunjukkan subclass atau subordinate dari suatu benda (head).

8. Bachelor degree from reputable state university (Bachelor adalah salah satu jenis/subclass dari degree di universitas)

9. strong communication skills (communication adalah salah satu jenis keterampilan/skill) 
Postmodifier adalah frasa atau klausa yang merupakan bagian dari frasa nomina dan terletak setelah head. Postmodifier tersebut memiliki fungsi sebagai qualifier. Secara struktur, postmodifier bisa berupa non-finite clause, finite clause, dan prepositional phrase.

10. the ability to understand company business performance

11. work experience in international donor project

12. bachelor degree from reputable state university

\section{METODE PENELITIAN}

Penelitian ini menggunakan metode documentary study. Dalam documentary study, teks atau naskah seperti publikasi pemerintah, publikasi ilmiah, surat kabar, majalah, dan novel digunakan sebagai sumber data (Bailey dalam Ahmed: 2010). Metode ini berguna untuk meneliti, mengkategorikan, menganalisis, dan menginterpretasikan data fisik berupa dokumen tertulis (Payne dan Payne dalam Ahmed: 2010).

Iklan-iklan lowongan pekerjaan berbahasa Inggris yang terdapat pada surat kabar lokal dan nasional berbahasa Indonesia digunakan sebagai instrument untuk mencari data. Surat kabar lokal yang dipilih adalah Pikiran Rakyat. Surat kabar ini diterbitkan dan diedarkan di wilayah Bandung dan di sekitar Jawa Barat dengan jumlah pembaca paling besar. Sementara, surat kabar nasional yang dipilih adalah Kompas karena surat kabar ini memiliki pembaca yang paling luas di antara surat kabar nasional lainnya. Terdapat 50 iklan lowongan pekerjaan berbahasa Inggris (11.9\%) dari total 420 iklan lowongan pekerjaan yang ditemukan di dalam surat kabar tersebut yang diedarkan dari bulan Juni hingga Juli 2016. Jumlah ini merupakan porsi yang cukup banyak berdasarkan jumlah iklan yang terdapat di surat kabar berbahasa Indonesia.

Kajian isi atau content analysis adalah teknik yang digunakan untuk menganalisis data. Kajian isi adalah teknik penelitian yang digunakan untuk menarik kesimpulan melalui usaha menemukan karakteristik pesan, dan dilakukan secara objektif dan sistematis (Holsti dalam Moloeng: 2015). Payne \& Payne dalam Sarosa (2012) mendefinisikan kajian isi sebagai cara mencari data tertulis secara sistematis dan terinci berdasarkan kategori yang ditentukan sebelumnya. 
Analisis data dilakukan pada saat pengumpulan data dan setelah pengumpulan data. Pada saat pengumpulan data, penulis menganalisis jenis bahasa yang digunakan pada iklan lowongan pekerjaan sementara itu, setelah pengumpulan data, penulis menganalisis nomi alisasi yang terdapat pada isi atau teks iklan lowongan.

\section{HASIL DAN PEMBAHASAN}

\section{Struktur nominalisasi yang terdapat dalam iklan lowongan pekerjaan}

Berdasarkan kajian yang dilakukan terhadap nominalisasi pada iklan lowongan pekerjaan berbahasa Inggris di media cetak berbahasa Indonesia, ditemukan bahwa semua nominalisasi memiliki struktur yang kompleks. Nominalisasi yang kompleks adalah nominalisasi sederhana ditambah beberapa elemen tambahan seperti numerative, epithet, classifier, dan qualifier. Dengan demikian, semua nominalisasi yang ditemukan terdiri atas satu nomina utama (head) dan atau determiner, numerative, epithet, classifier, dan qualifier.

Di bawah ini merupakan contoh nominalisasi kompleks yang digunakan pada iklan lowongan pekerjaan.

Intermediate proficiency level of Microsoft Office

\begin{tabular}{|l|l|c|c|}
\hline Intermediate & proficiency & level & of Microsoft Office \\
\hline Epithet & Classifier & Thing & Qualifier \\
\hline
\end{tabular}

Self-motivated, energetic, creative individual

\begin{tabular}{|c|l|l|l|}
\hline $\begin{array}{c}\text { Self- } \\
\text { motivated }\end{array}$ & energetic & creative & individual \\
\hline Classifier 1 & Classifier 2 & Classifier 3 & Thing \\
\hline
\end{tabular}

Bachelor degree with good English skill

\begin{tabular}{|l|l|l|}
\hline Bachelor & degree & with good English skill \\
\hline Classifier & Thing & Qualifier \\
\hline
\end{tabular}




\section{Experience in the same position}

\begin{tabular}{|l|l|}
\hline Experience & in the same position \\
\hline Thing & Qualifier \\
\hline
\end{tabular}

Master degree from reputable university

\begin{tabular}{|l|l|l|}
\hline Master & degree & from reputable university \\
\hline Classifier & Thing & Qualifier \\
\hline
\end{tabular}

Proven track records in strategic leadership experience

\begin{tabular}{|c|c|c|c|}
\hline Proven & track & records & in strategic leadership experience \\
\hline Epithet & Classifier & Thing & Qualifier \\
\hline
\end{tabular}

Demonstrated ability to execute vision and mission of organization

\begin{tabular}{|c|c|c|}
\hline Demonstrated & ability & to execute vision and mission of organization \\
\hline Classifier & Thing & Qualifier \\
\hline
\end{tabular}

Advance understanding in development and implementation of Tri Dharma Perguruan Tinggi

\begin{tabular}{|r|c|c|}
\hline Advance & understanding & $\begin{array}{l}\text { in development and implementation of Tri Dharma } \\
\text { Perguruan Tinggi }\end{array}$ \\
\hline Epithet & Thing & Qualifier \\
\hline
\end{tabular}

\section{Excellent communication skills in both Bahasa and English}

\begin{tabular}{|l|l|r|c|}
\hline Excellent & communication & skills & in both Bahasa and English \\
\hline Epithet & Classifier & Thing & Qualifier \\
\hline
\end{tabular}

Ability to make decisions

\begin{tabular}{|l|l|}
\hline Ability & to make decisions \\
\hline Thing & Qualifier \\
\hline
\end{tabular}


Experience in finance and accounting

\begin{tabular}{|l|l|}
\hline Experience & in finance and accounting \\
\hline Thing & Qualifier \\
\hline
\end{tabular}

Good English communication skill

\begin{tabular}{|l|l|l|l|}
\hline Good & English & communication & skill \\
\hline Epithet & Classifier 1 & Classifier 2 & Thing \\
\hline
\end{tabular}

Excellent computer and typing skills

\begin{tabular}{|l|l|l|l|}
\hline Excellent & computer & typing & skills \\
\hline Epithet & Classifier 1 & Classifier 2 & Thing \\
\hline
\end{tabular}

\section{Excellent standard English}

\begin{tabular}{|l|l|l|}
\hline Excellent & standard & English \\
\hline Epithet & Classifier & Thing \\
\hline
\end{tabular}

Experience in teaching business studies

\begin{tabular}{|l|l|}
\hline Experience & in teaching business studies \\
\hline Thing & Qualifier \\
\hline
\end{tabular}

\section{Experience in the field of marketing}

\begin{tabular}{|l|l|}
\hline Experience & in the field of marketing \\
\hline Thing & Qualifier \\
\hline
\end{tabular}

Good communication skill

\begin{tabular}{|l|l|l|}
\hline Good & communication & skill \\
\hline Epithet & Classifier & Thing \\
\hline
\end{tabular}


Advanced skill in computer application

\begin{tabular}{|l|l|c|}
\hline Advanced & skill & in computer application \\
\hline Epithet & Thing & Qualifier \\
\hline
\end{tabular}

Excellent communication skills in English and Bahasa

\begin{tabular}{|l|l|c|c|}
\hline Excellent & communication & skills & in English and Bahasa \\
\hline Epithet & Classifier & Thing & Qualifier \\
\hline
\end{tabular}

Experience in finance and marketing

\begin{tabular}{|l|l|}
\hline Experience & in finance and marketing \\
\hline Thing & Qualifier \\
\hline
\end{tabular}

An excellent visionary leadership

\begin{tabular}{|l|l|l|l|}
\hline An & excellent & visionary & leadership \\
\hline Deictic & Epithet & Classifier & Thing \\
\hline
\end{tabular}

Good communication skill in English and Mandarin

\begin{tabular}{|l|l|l|l|}
\hline Good & communication & skill & in English and Mandarin \\
\hline Epithet & Classifier & Thing & Qualifier \\
\hline
\end{tabular}

A Bachelor degree holder in Management

\begin{tabular}{|l|l|l|l|r|}
\hline A & Bachelor & degree & holder & in Management \\
\hline Deictic & Classifier 1 & Classifier 2 & Thing & Qualifier \\
\hline
\end{tabular}

Good interpersonal skill

\begin{tabular}{|l|l|l|}
\hline Good & interpersonal & skill \\
\hline Epithet & Classifier & Thing \\
\hline
\end{tabular}


Ability to operate computer and internet

\begin{tabular}{|l|l|}
\hline Ability & to operate computer and internet \\
\hline Thing & Qualifier \\
\hline
\end{tabular}

A law degree from reputable university

\begin{tabular}{|l|l|c|c|}
\hline A & law & degree & from reputable university \\
\hline Deictic & Classifier & Thing & Qualifier \\
\hline
\end{tabular}

Good communication

\begin{tabular}{|l|l|}
\hline Good & communication \\
\hline Epithet & Thing \\
\hline
\end{tabular}

Good attitude

\begin{tabular}{|l|l|}
\hline Good & attitude \\
\hline Epithet & Thing \\
\hline
\end{tabular}

\section{Penggunaan nominalisasi dalam iklan lowongan pekerjaan}

Nominalisasi pada iklan lowongan pekerjaan tersebar di semua bagian iklan lowongan pekerjaan, yaitu pada bagian awal iklan lowongan pekerjaan (headline), bagian isi iklan lowongan pekerjaan (body), dan bagian akhir iklan lowongan pekerjaan. Tabel berikut ini menunjukkan jumlah persentasi sebaran nominalisasi yang terdapat pada iklan lowongan pekerjaan.

Tabel 1

Persentasi Sebaran Nominalisasi yang Ditemukan Pada Iklan Lowongan Pekerjaan

\begin{tabular}{|c|c|c|}
\hline Bagian iklan & Jumlah & Persentasi \\
\hline awal (headline) & 22 & $4 \%$ \\
\hline tengah (body) & 479 & $94 \%$ \\
\hline akhir & 8 & $2 \%$ \\
\hline jumlah & 509 & $100 \%$ \\
\hline
\end{tabular}


Headline merupakan bagian awal dari iklan lowongan pekerjaan dan dianggap sebagai bagian yang inti dari sebuah iklan lowongan pekerjaan. Menurut Albert (dalam Hong: 2011), headline memiliki tujuan untuk menarik perhatian pembaca sehingga mereka kemudian membaca iklan tersebut.Secara struktur, bagian awal iklan lowongan pekerjaan terdiri atas beberapa informasi seperti nama pekerjaan yang ditawarkan, nama perusahaan atau instansi pencari tenaga kerja, lokasi kerja, dan informasi singkat tentang perusahaan. Pada penelitian ini, terdapat 22 nominalisasi yang ditemukan pada bagian headline iklan lowongan pekerjaan. Nominalisasi tersebut merupakan informasi tentang nama perusahaan seperti Susu Air, Ultrajaya Milk Industry; nama pekerjaan yang ditawarkan seperti General Affair Manager, HR Manager, Finance Manager, dan Fulltime Lecrturer; dan pemberitahuan tentang iklan lowongan itu sendiri seperti Job Vacancy, Career Opportunities, dan Vacant Position.

Bagian tengah merupakan bagian yang paling informatif dan persuasif dari iklan lowongan pekerjaan karena bagian ini menampilkan informasi mengenai deskripsi singkat tentang pekerjaan yang ditawarkan seperti persyaratan untuk melamar pekerjaan dan tugas serta kewajiban yang akan dilakukan apabila diterima untuk bekerja di perusahaan pengiklan. Pada penelitian ini, nominalisasi hanya ditemukan pada bagian persyaratan sedangkan pada bagian tugas dan kewajiban dibuat dalam struktur kalimat sederhana. Untuk bagian persyaratan, bentuk nominalisasi yang digunakan adalah seperti excellent interpersonal and communication skills, strong problem solving capability, high level competence in the relevant technology, passion for growth, knowledge of JDE World, dan bachelor degree from any discipline.

Bagian akhir iklan lowongan pekerjaan berisi tentang tata cara melamar pekerjaan yang disertai dengan informasi alamat untuk mengirimkan surat lamaran pekerjaan dan curriculum vitae, serta informasi tentang tanggal batas akhir pengiriman surat lamaran pekerjaan. Pada penelitian ini, nominalisasi ditemukan pada nama penerima surat lamaran pekerjaan dan informasi tentang batas akhir pengiriman surat lamaran pekerjaan seperti HR Department, HRD Division of English First Bandung, Embassy of Switzerland, dan Closing date. 


\section{SIMPULAN}

Penelitian ini menganalisis nominalisasi yang terdapat pada iklan lowongan pekerjaan di surat kabar regional dan nasional berbahasa Indonesia. Surat kabar yang digunakan adalah surat kabar Pikiran Rakyat dan surat kabar Kompas karena surat kabar tersebut mempunyai wilayah penyebaran yang paling luas di antara surat kabar regional dan nasional lainnya. Terdapat 50 iklan lowongan pekerjaan berbahasa Inggris (11.9\%) dari total 420 iklan lowongan pekerjaan yang ditemukan di dalam surat kabar tersebut yang diedarkan dari bulan Juni hingga Juli 2016.

Berdasarkan kajian yang dilakukan, ditemukan bahwa semua nominalisasi yang dianalisis merupakan nominalisasi kompleks. Hal ini berarti semua bentuk nominalisasi yang ditemukan terdiri atas satu nomina utama (head) dan atau determiner, numerative, epithet, classifier, dan qualifier. Contoh frasa nomina kompleks adalah advanced skill in computer application, excellent communication skills in English and Bahasa, experience in finance and marketing, an excellent visionary leadership, dan good communication skill in English and Mandarin. Selain itu, data menunjukkan bahwa nominalisasi digunakan pada semua bagian iklan lowongan pekerjaan; bagian awal (headline), bagian tengah (body), dan bagian akhir (closing). Pada penelitian ini, terdapat 22 nominalisasi yang ditemukan pada bagian headline iklan lowongan pekerjaan yang merupakan informasi tentang nama perusahaan seperti Susu Air, Ultrajaya Milk Industry; nama pekerjaan yang ditawarkan seperti General Affair Manager, HR Manager, Finance Manager, dan Fulltime Lecrturer; dan pemberitahuan tentang iklan lowongan itu sendiri seperti Job Vacancy, Career Opportunities, dan Vacant Position. Pada bagian tengah, nominalisasi hanya ditemukan pada bagian persyaratan seperti excellent interpersonal and communication skills, strong problem solving capability, high level competence in the relevant technology, passion for growth, knowledge of JDE World, dan bachelor degree from any discipline. Pada bagian akhir, frasa nomina ditemukan pada nama penerima surat lamaran pekerjaan dan informasi tentang batas akhir pengiriman surat lamaran pekerjaan seperti HR Department, HRD Division of English First Bandung, Embassy of Switzerland, dan Closing date. 


\section{DAFTAR PUSTAKA}

Ahmed, J.U. (2010). Documentary Research Method: New Dimensions.Indus Journal of Management \& Social Sciences, 4(1): 1-14.

Bello, Iria. (2016). Cognitive Implications of Nominalizations in the Advancement of Scientific Discourse. International Journal of English Studies (IJES). University of Murcia. 16 (2): 1-23. https://doi.org/10.6018/ijes/2016/2/262921

Cooper, Jesica. (2010). Nominalization. [Online].Tersedia: $\quad$ [15 Mei 2016].

Dessler, Gary. (2013). Human Resource Management-Thirteenth Edition. New Jersey: Pearson.

Eggins, Suzanne. (2004). An Introduction to Systemic Functional Linguistics $2^{\text {nd }}$ Edition. London: Contimuum.

Hong, Nguyen Thi Phuong. (2011). A Discourse Analysis of Job Advertisements in English and Vietnamese. A thesis Summary.University of Danang.

Kheovichai, Baramee. (2013). Marketization in the language of University Recruitment: A Critical Discourse Analysis and Corpus Comparison of University and Finance Industry Job Advertisement. Unpublished Doctoral Dissertation. University of Birmingham, UK.

Kim, Jeonghyun. et al. (2013). Competencies Required for Digital Curation: An Analysis of Job Advertisements. The International Journal of Digital CURATION. 8 (1): $66-83$.

Knapp, Peter and Megan Watkins. (2009). Genre, Text, Grammar: Technologies for teaching and assessing writing. Sydney: University of New South Wales Press Ltd.

Lapsanska, Jana. (2006). The Language of Advertising with The Concentration on The Linguistic Means and The Analysis of Advertising Slogans. Univerzuta Komenskeho V Bratislave.

Leech, Geoffrey N. English in advertising: a linguistic study of advertising in Great Britain. 1st ed. London: Longmans, 1966. Print. 
Moleong, Lexy.(2015). Metodologi Penelitian Kualitatif Edisi Revisi. Bandung: Rosdakarya.

Oshima, Alice dan Ann Hogue. (2006). Writing Academic English 4th Edition. Longman: Pearson Education.

Romanenko, Elena. (2014). Linguistic Analysis of Online Advertising. Charles University in Prague. Faculty of Education. Department of English Language and Literature.

Reaction Search International (RSI). (2013). What Qualifies as a 'Good' Job Advertisements? [Online].Tersedia: [19 Maret 2016].

Sarosa, Samiaji. (2012). PeneltianKualitatif: Dasar-dasar. Jakarta: Indeks.

Vaicenoniene, Jurgita. (2006). The Language of Advertising: Analysis of English and Lithuanian Advertising Text. KalbuStudijos. 9: 43-55.

Martin, J. R., 1991. Nominalization in Science and Humanities: Distilling Knowledge and Scaffolding Text, in Ventola, E. (ed.). Functional and Systematic Linguistics: Approaches 